\title{
Estimation of Canopy Area of Fruit Trees Using Light Unmanned Aerial Vehicle (UAV) and Image Processing Methods"
}

\author{
Adil Koray Yıldız ${ }^{1, a}$, Hakan Keles, ${ }^{2, b}$, Servet Aras ${ }^{2, c, *}$ \\ ${ }^{1}$ Department of Biosystem Engineering, Faculty of Engineering and Architecture, Yozgat Bozok University, 66200 Yozgat, Turkey \\ ${ }^{2}$ Department of Horticulture, Faculty of Agriculture, Yozgat Bozok University, 66200 Yozgat, Turkey \\ *Corresponding author

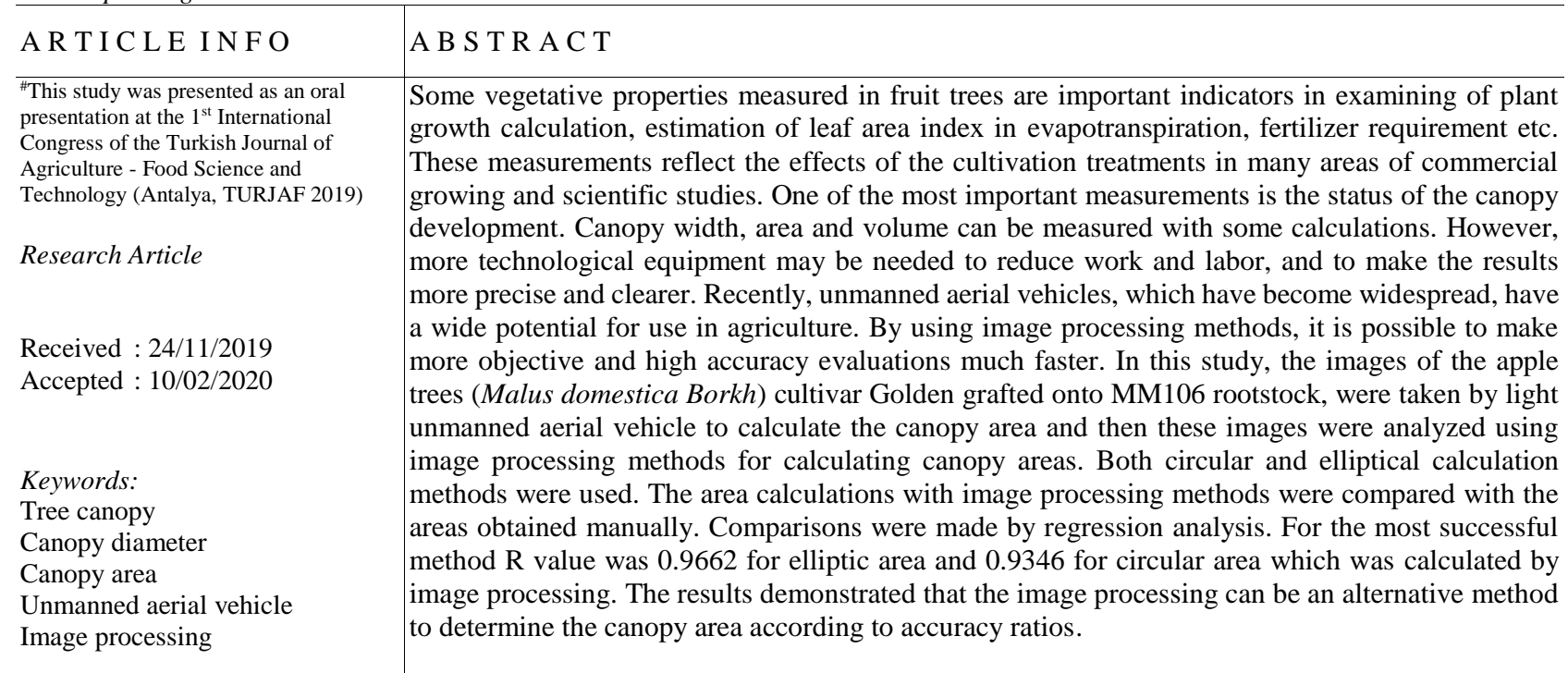

adilkoray.yildiz@bozok.edu.tr

servet.aras@bozok.edu.tr

\section{(iD https://orcid.org/0000-0002-6472-5276

hakan.keles@bozok.edu.tr

(iD) https://orcid.org/0000-0002-8225-931X

\section{Introduction}

Tree canopy is one of the most important parameters for evaluation of plant growth. An increase in tree canopy leads to increment in shoots, leaves, thus photosynthesis; however, it decreases dwarfing capability of the plant. Dwarf trees offer many cultural advantages to producers such as pruning, fertilization, pesticide application. Dwarfing in trees can be obtained by correct pruning, using dwarf rootstocks and optimum fertilization. Therefore, canopy must be restricted by pruning and other treatments in order to provide a smaller size of habitus. In that case, measurement of tree canopy area possesses importance to keep trees in a small size in orchards. Furthermore, canopy size could also provide productivity information on trees. Canopy area can be measured with some formula reported in Peek (1970), however, it is time-consuming due to measurement of canopy diameter and calculating on the formulae. Accurate and rapid canopy area estimates are critical in orchards. Recently, remote sensing appliances with digital image processing software have largely replaced older methods to measure the area or volume of a part of plants. Most of the digital image processing studies were conducted on estimation of leaf area index (Casa et al., 2019), however, the digital image processing studies for canopy area of trees is still limited. In a previous experiment, Johnson et al. (2003) studied estimation of vineyard leaf area with multispectral satellite imagery. Yamamoto (2000) estimated canopy gap size with an image processing program using Delphi 5.0J. Canopy projection area of broccoli was estimated by using digital image processing software by Yildiz et al. (2017).

Images to be processed can be taken by using handheld cameras. However, if you want to work with larger areas or bigger plants like trees, it is possible to take images with the help of aerial vehicles. Recently, many commercial Unmanned Aerial Vehicles (UAV) have been developed. The use of UAV has become widespread in many areas as a result of technological developments reducing costs. It is used especially for monitoring plants in the agricultural 
field (Kim et al., 2019). Since the images are easier to obtain and therefore to be evaluated, the use of light UAVs on non-wide agricultural lands is more preferred than the images obtained by aircraft or satellite. The analysis can be performed by using images obtained with digital RGB (Red-Green-Blue) cameras (Yeom et al., 2019), and the use of multispectral cameras provides great benefits (Zhou and Jiang, 2019). However, the use of multispectral cameras increases the cost.

Less attention has been paid to estimate canopy area in orchards. The main purpose of the current study was to estimate canopy area of apple trees by processing digital RGB images which have been taken by light UAV. In the study, the possible relation between the canopy area calculated with a formula and the area determined from digital image processing was examined.

\section{Material and Methods}

The study was carried out at the Yozgat Bozok University Experiment Orchard in September in 2019. Sixyear-old apple cultivar Golden Delicious grafted onto MM106 rootstock was used in the study. The experiment was arranged in a randomized plot design with three replicates of fifteen plants per replication. Tree spacing was $1.5 \mathrm{~m} \times 5 \mathrm{~m}$. Trees were irrigated through drip lines as needed and average annual precipitation of the district was $554 \mathrm{~mm}$. Tree shaping was based on encouraging development of the leader.

The canopy area measurement included leaves and shoots. There are two ways for calculating the area of tree canopy: elliptical and circular (Peek, 1970). For the calculation of elliptical canopy areas, two distance measurements were taken from the extreme points using a tape in the east-west and south-north orientation (Figure 1). The elliptic area was calculated by these measurements. For the calculation of the circular area, the two furthest points determined by just looking in the tree canopy were measured and recorded.

DJI Mavic Pro (SZ DJI Technology Co., Shenzhen, China) was used as UAV. This UAV is a 743 gram and 335 mm wide, four-rotor, multi-copter. It has about 27 minutes of flight time. It takes images with a 12.35-megapixel CMOS camera. The tree images were taken while the tree trunk was at the center of the picture, at a height of $10 \mathrm{~m}$ from the ground, at a right angle, with the automatic white balance setting. Figure 2 shows an example from the images. Twenty trees of different sizes were photographed on a single row. In order to separate the tree images from the ground easily, weeds were cleaned by tillage before the images were taken.

In order to take the required measurements from the images, first, the RGB format was transformed to HSV (Hue, Saturation, Value). The study continued the grayscale image obtained from the Hue values (Figure 3A). Since the pixel values in the parts of the tree in this image were generally between 50 and 100, it is converted to black and white (BW) image by converting pixels between these values to white (Figure 3B). Afterward a detailed area image of the tree was obtained and recorded by performing morphological processes such as dilate, erode, spacefilling, deletion of small objects and boundary objects on the BW image (Figure 3C).

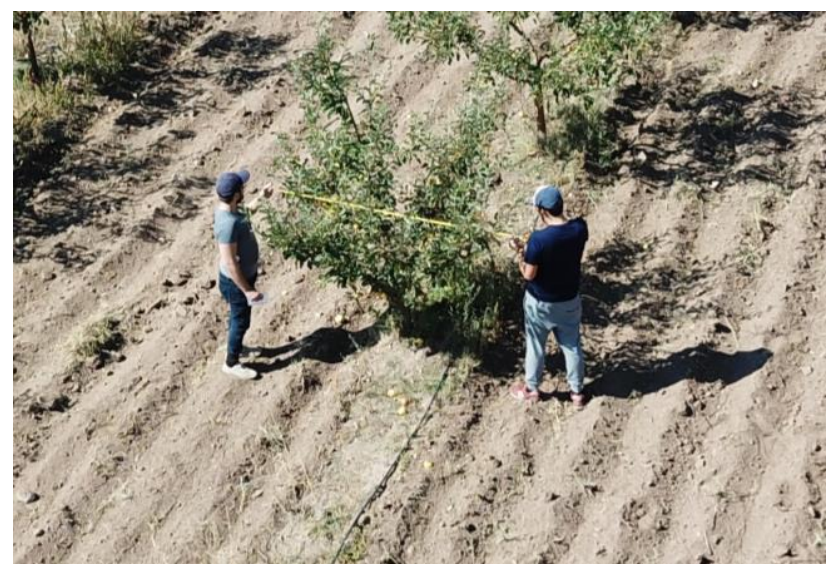

Figure 1. Measurements with tape measure

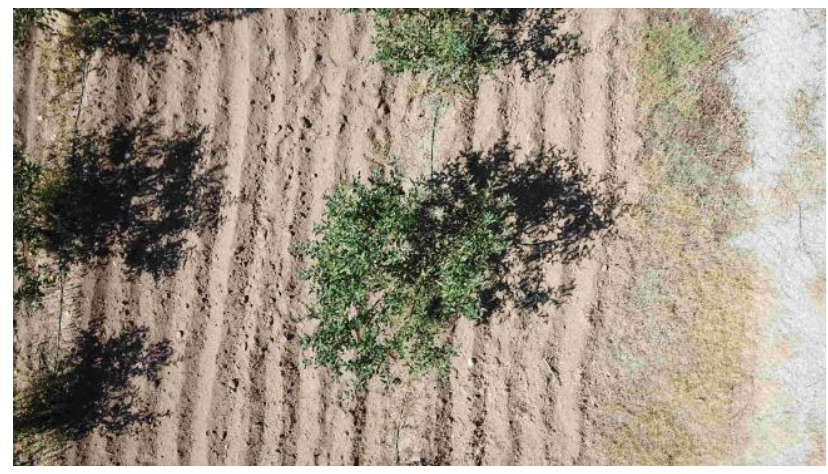

Figure 2. An example of a tree photo

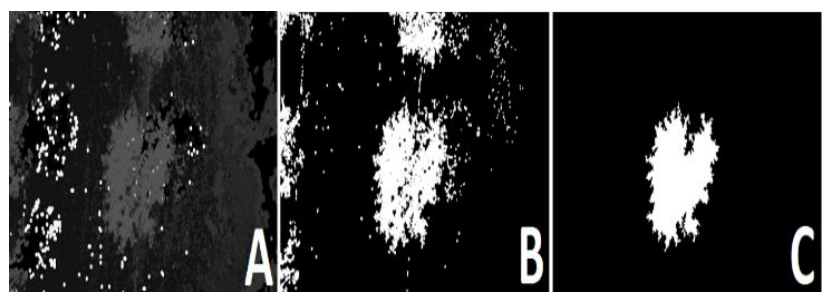

Figure 3. Image processing stages. (A: Grayscale, B: Black-White, C: Detailed Black-White)
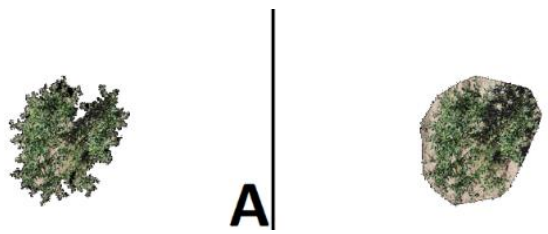

Figure 4. Masking the area images with the actual images (A: Detailed, B: Convex)

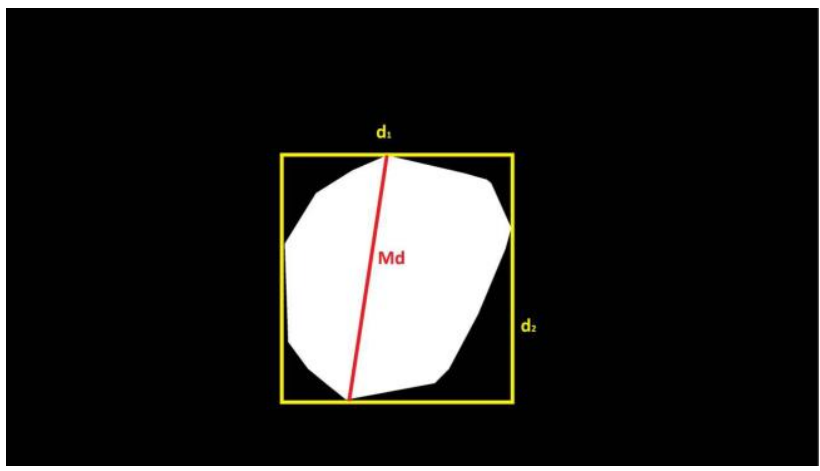

Figure 5. Horizontal, vertical distances and maximum diameter of convex image 
The detailed image was combined at the endpoints to obtain a convex area image than recorded. In Figure 4, the processed images as a result of masking the area with the actual images are given. As shown in the figure, the plant was sufficiently segmented from the environment.

Using the convex image, the horizontal and vertical distances are recorded for the elliptical area and the distance of the two furthest points on the object which is named maximum diameter $\left(\mathbf{M}_{\mathrm{d}}\right)$ for the circular area (Figure 5.).

The area calculations by using these records obtained by image processing and measurements are given in Table 1.

In Table $1 ; R$ is the circular diameter, $D_{1}$ and $D_{2}$ are elliptical diameters measured by tape. $M_{d}$ is the maximum diameter of the convex image and, $\mathrm{d}_{1}$ and $\mathrm{d}_{2}$ are respectively the width and height of the boundary rectangle. $\mathrm{P}_{1}$ is the pixel values in the BW image. The sum function returns the area value of the white object in pixels.

Image processing was performed by using LABVIEW software and VISION plug-in. Statistical analysis was performed with regression analysis. The magnitudes in the images are pixel values. The value of actual length in $\mathrm{cm}$ per pixel was calculated using reference geometry. For this purpose, an image of reference circular objects which actual dimensions are known was taken from the same height as the trees. The five circular blue objects shown in Figure 6 were converted to the gray image by using the blue color field. Then, the diameters of objects were determined in pixels by the circle capture function. The known actual diameter of the object was divided by the average of these calculated diameters to obtain the calibration value. All values obtained by image processing were calibrated to the actual dimensions with the help of this calibration value.

\section{Results and Discussion}

Two different area images were obtained for each photo of trees. The area values obtained from the images and determined the field measurements were compared with regression analysis. The areas determined the field measurements were also compared with the areas calculated by summing of image pixels for both detailed and convex BW images. Regression graphs for the circular area are given in Figure 7.

Regression graphs for the elliptical area are also given in Figure 8.

The calculated $\mathrm{R}$ values for all comparisons are summarized in Table 2.
In this study, it has been shown that the canopy areas can be calculated in a similar way to the classical method by processing the images taken by UAVs. Thus, a new method for calculating the canopy area was introduced. It is possible to take images with automatic flights at certain time intervals. In future studies, plant growth can be monitored by processing and evaluating these images.

Table 1. Equations used for area calculations

\begin{tabular}{l|c}
\hline Area & Function \\
\hline Measured Circular & $\pi \times(\mathrm{R} / 2)^{2}$ \\
Measured Elliptical & $\left(\pi \times \mathrm{D}_{1} \times \mathrm{D}_{2}\right) / 4$ \\
Calculated Circular & $\pi \times\left(\mathrm{M}_{\mathrm{d}} / 2\right)^{2}$ \\
Calculated Elliptical & $\left(\pi \times \mathrm{d}_{1} \times \mathrm{d}_{2}\right) / 4$ \\
Detailed BW Image & $\sum\left(\mathrm{P}_{1}\right)$ \\
& $\sum\left(\mathrm{P}_{1}\right)$ \\
\hline
\end{tabular}

Table 2. $\mathrm{R}$ values between the areas of field measured and image analyses

\begin{tabular}{l|cc}
\hline \multirow{2}{*}{\multicolumn{1}{c|}{ Area Type }} & \multicolumn{2}{c}{ Calculation type } \\
\cline { 2 - 3 } & Circular & Elliptical \\
\hline Calculated & 0.9346 & 0.9662 \\
Detailed BW Image & 0.6868 & 0.7427 \\
Convex BW Image & 0.8840 & 0.9356 \\
\hline
\end{tabular}

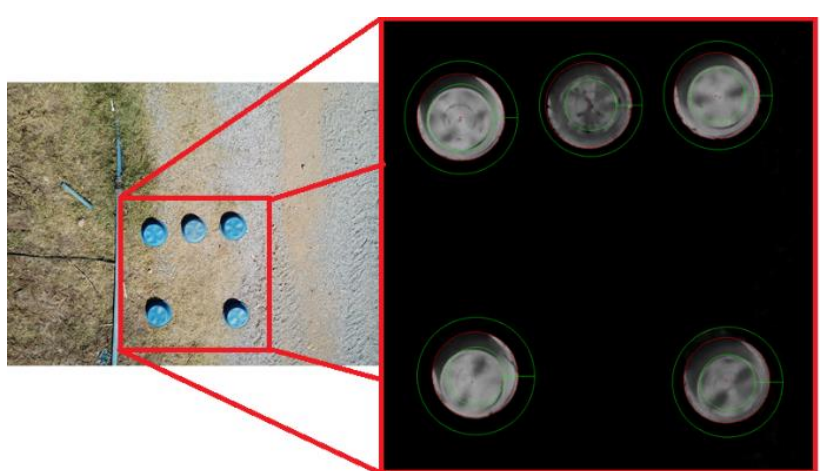

Figure 6. Reference circular objects and results of the circle capture function
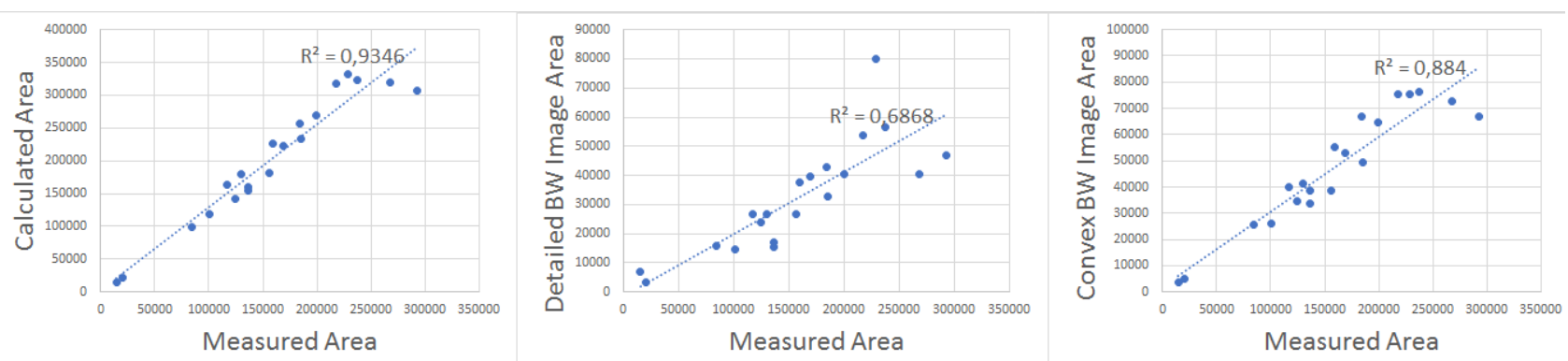

Figure 7. Regression graphs for circular area $\left(\mathrm{cm}^{2}\right)$ comparisons 

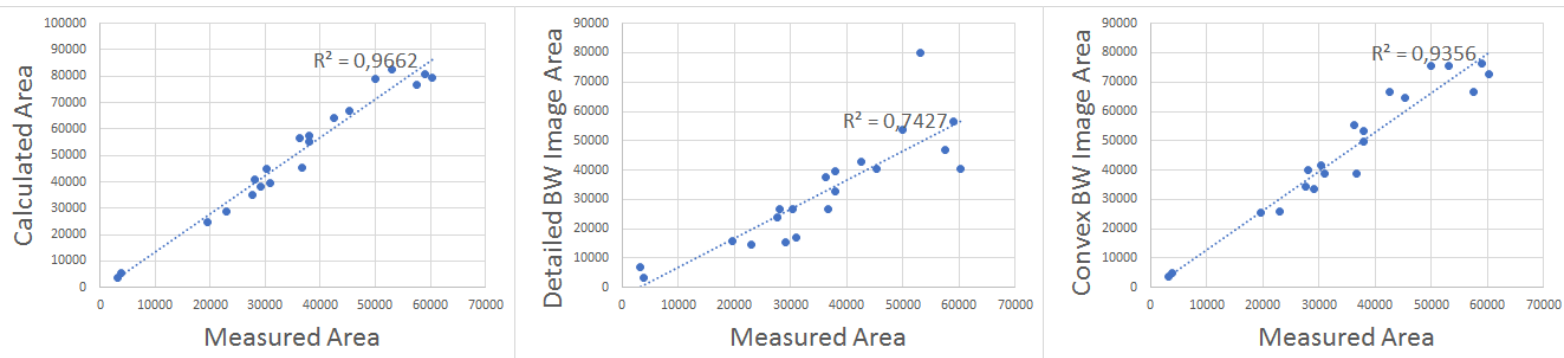

Figure 8. Regression graphs for elliptic area comparisons

As seen in Table 2, the areas obtained by image measurements for both calculations are closer to the actual measurements. When these area calculations were compared with the classical method, it was found that the most successful method was calculated with $\mathrm{d} 1$ and $\mathrm{d} 2$ on the convex image whose $\mathrm{R}$ value was 0.9662 for elliptic area and 0.9346 for circular area. BW image areas are more realistic for representing the real area. Especially, if the detailed image mask is examined, it is understood that the area was very precisely separated from the ground (see Figure 3A). However, different results were obtained according to the calculation method in the literature. Therefore, although it gives realistic results, it is not an alternative to the classical method.

\section{References}

Casa R, Upreti D, Pelosi F. 2019. Measurement and estimation of leaf area index (LAI) using commercial instruments and smartphone-based systems, IOP Conference Series: Earth and Environmental Science. Institute of Physics Publishing. https://doi.org/1 0.1088/1755-1315/275/1/012006
Johnson LF, Roczen DE, Youkhana SK, Nemani RR, Bosch DF. 2003. Mapping vineyard leaf area with multispectral satellite imagery. Computers and electronics in agriculture. 38(1): 3344.

Kim J, Kim S, Ju C, Son H. 2019. Unmanned Aerial Vehicles in Agriculture: A Review of Perspective of Platform, Control, and Applications. IEEE Access 7. 105100-105115. https://doi.org/ 10.1109/access.2019.2932119

Peek JM. 1970. Relation of canopy area and volume to production of three woody species. Ecologyç 51(6):1098-1101.

Yamamoto K. 2000. Estimation of the canopy-gap size using two photographs taken at different heights. Ecological Research. 15(2):203-208.

Yeom J, Jung J, Chang A, Ashapure A, Maeda M, Maeda A, Landivar J. 2019. Comparison of vegetation indices derived from UAV data for differentiation of tillage effects in agriculture. Remote Sens. 11. https://doi.org/ $10.3390 /$ rs 11131548

Yıldız AK, Öztekin T, Cömert MM. 2017. Brokoli Taç İzdüşüm Alanının Görüntü İşleme Yöntemi Kullanılarak Hesaplanması. Gaziosmanpaşa Üniversitesi Ziraat Fakültesi Dergisi. 34:173-178.

Zhou YM, Jiang MJ. 2019. Comparison of inversion method of maize leaf area index based on UAV hyperspectral remote sensing. Multimed. Tools Appl. https://doi.org/ 10.1007/s11042-019-7318-9 